\title{
REGENERATION OF BONE AFTER LOSS OF THE DISTAL HALF OF THE HUMERUS
}

\author{
Ö. ÜLKÜ, V. KARATOSUN \\ From the State Hospital, Izmir, Turkey,
}

CASE REPORT WITH A 20-YEAR FOLLOW-UP

\begin{abstract}
A 16-year-old boy was involved in an agricultural accident in which he sustained a large wound to the right arm and forearm. Radiological examination showed loss of the distal half of the humerus. A posterior splint was applied and after two months there was regeneration of the distal humerus including the articular portion. He was able to use his arm at five months. Twenty years later, he had a painless elbow and a $70^{\circ}$ range of movement.
\end{abstract}

J Bone Joint Surg [Br] 1997;79-B:746-7.

Received 24 February 1997; Accepted 8 April 1997

Open fractures with loss of a large segment of bone usually require complex reconstructive procedures. We describe such a case which was treated only by a posterior splint for two months. When seen 20 years later there was regeneration of bone, including the joint surface, and excellent function.

\section{CASE REPORT}

In 1976 a 16-year-old boy was admitted with an open wound in his right arm as a result of an agricultural accident in which the arm had been rolled into a heavy machine. The wound extended from $10 \mathrm{~cm}$ above the elbow to about $15 \mathrm{~cm}$ into the forearm. Radiography revealed loss of the distal half of the humerus. After debridement and irrigation of the wound a posterior splint was applied. All the local nerves and vessels were intact and almost all of the peri-

Ö. Ülkü, MD, Orthopaedic Surgeon and Chief of the Department V. Karatosun, MD, Orthopaedic Surgeon

Department of Orthopaedics, State Hospital, 35360 Izmir, Turkey.

Correspondence should be sent to Dr V. Karatosun at Mithatpasa Cad, No. 248/22, 35260 Izmir, Turkey.

(C1997 British Editorial Society of Bone and Joint Surgery 0301-620X/97/57713 \$2.00 osteum of the distal half of the humerus was in place. Later, the avulsed portion of the bone was recovered (Fig. 1).

The wound healed in two months, and regeneration of the missing segment, including the articular portion, was seen (Fig. 2). After five months (Fig. 3), the patient was able to use his arm without pain and had $70^{\circ}$ of movement at the elbow.

In 1996 when he was reviewed, he was working as a waiter. There had been no change in the range of movement (Figs 4 and 5).

\section{DISCUSSION}

In children the capacity of the periosteum to regenerate the diaphysis is well known. ${ }^{1,2}$ With increasing age, the periosteum becomes thinner, less vascular and the ability to form new bone decreases, but the potential to form bone or cartilage remains. ${ }^{1}$

A review of the literature produced only one report of regeneration of a large segment of bone, in an eight-yearold girl with loss of the proximal femur. ${ }^{2}$

Current thought advocates reposition and osteosynthesis of the detached fragment ${ }^{2}$ or reconstruction using an osteoarticular allograft or an implant. ${ }^{3,4}$ Application of a simple splint, however, may give the bone and articular surface a chance to regenerate, and this case emphasises the importance of preservation of the periosteum.

No benefits in any form have been received or will be received from a commercial party related directly or indirectly to the subject of this article.

\section{REFERENCES}

1. Buckwalter JA. Musculoskeletal tissues and the musculoskeletal system. In: Weinstein SL, Buckwalter JA, eds. Turek's orthopaedics. Principles and their application. Fifth ed. Philadelphia: JB Lippincott Company, 1994:13-67.

2. Pazzaglia UE, Finardi E, Pedrotti L, Zatti G. Fracture with loss of the proximal femur in a child: a case report. Int Orthop 1991;15: 143-4.

3. Terek RM. Tumors of the elbow and forearm. Hand Clin 1994; 10:543-51.

4. Windhager R, Millesi H, Kotz R. Resection-replantation for primary malignant tumours of the arm: an alternative to fore-quarter amputation. J Bone Joint Surg [Br] 1995;77-B:176-84. 


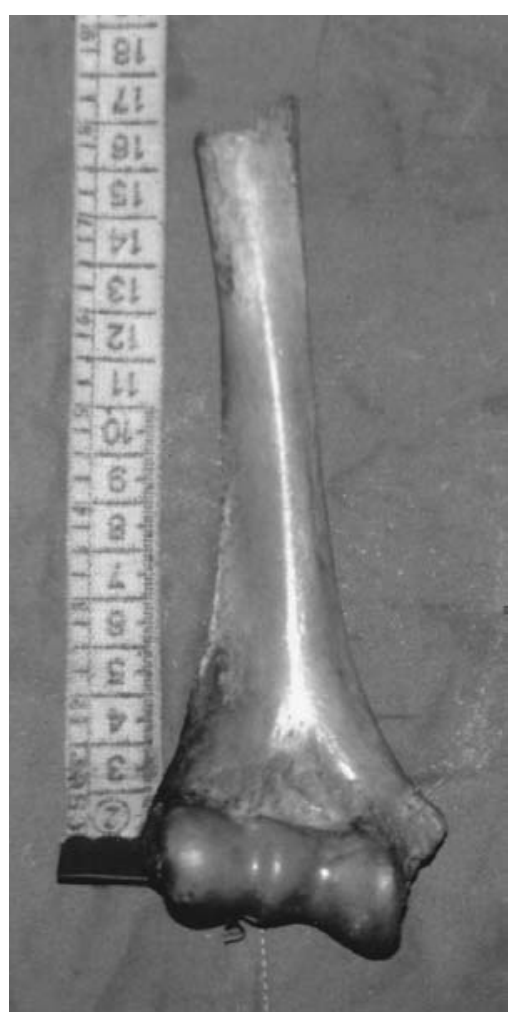

Fig. 1

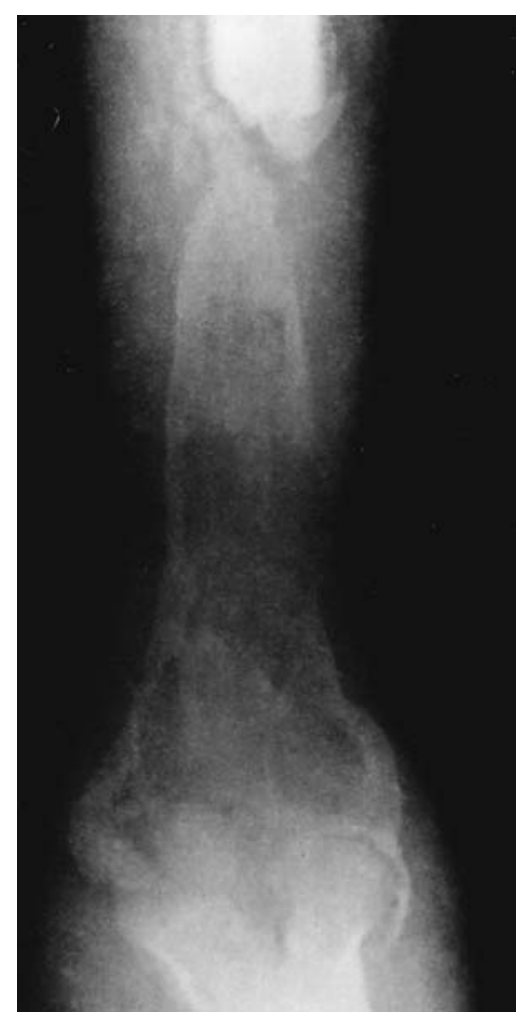

Fig. 2

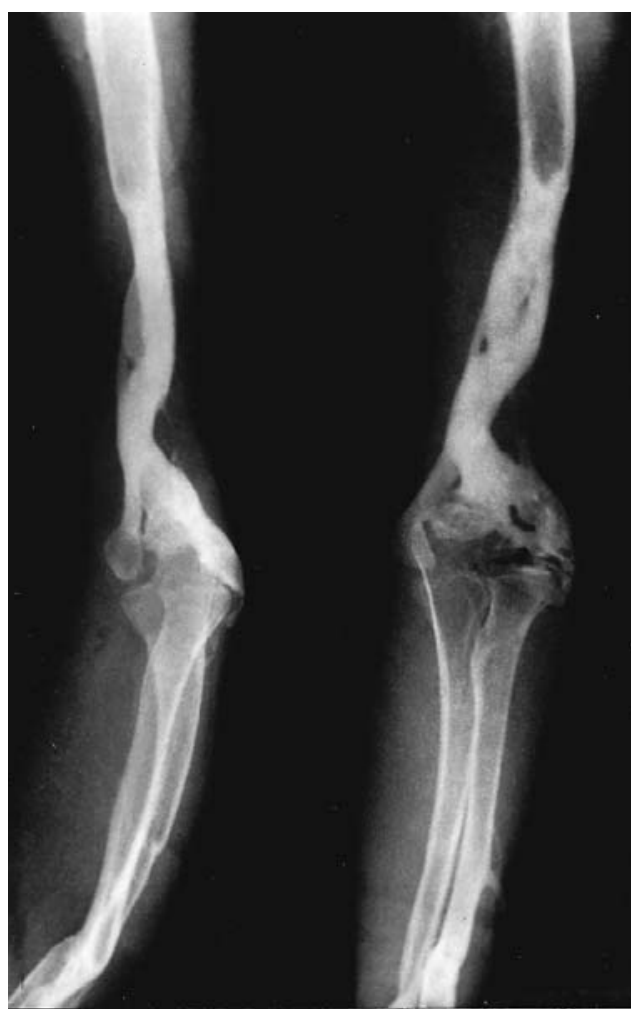

Fig. 3

A radiograph two months after injury showing regeneration of the distal humerus. after injury.

The avulsed segment of bone.

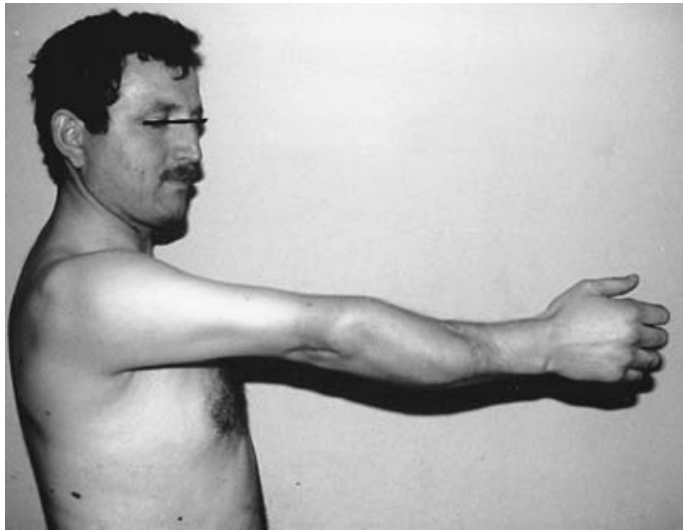

Fig. 4a

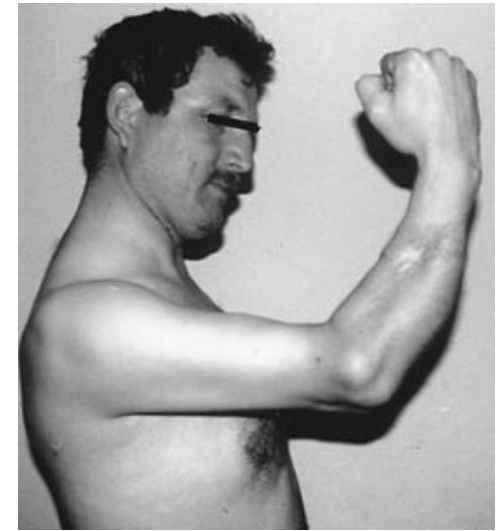

Fig. 4b

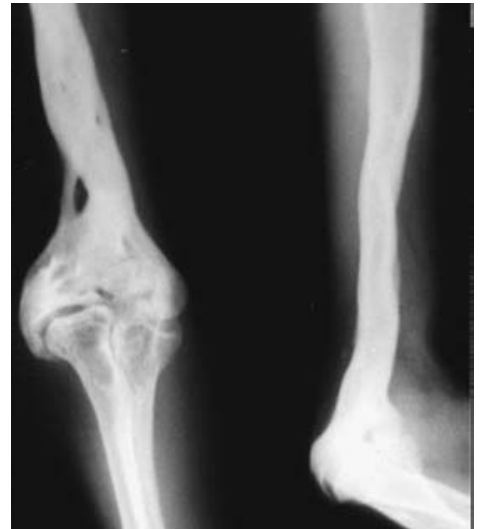

Fig. 5

The appearance (a) and range of movement in the elbow (b) 20 years after injury.

Anteroposterior and lateral radiographs 20 years after injury. 